Ensino, Saúde e Ambiente-V10 (3), pp. 159-170, Dez. 2017

\title{
A EDUCAÇÃO E A SAÚDE MENTAL DA POPULAÇÃO NEGRA
}

\section{THE EDUCATION AND MENTAL HEALTH OF THE BLACK POPULATION}

\author{
Abrahão de Oliveira Santos ${ }^{1}$ \\ ${ }^{1}$ Universidade Federal Fluminense/Instituto de Psicologia/Departamento de psicologia/Programa de Pós- \\ Graduação em Psicologia, abrahaosantos@hotmail.com
}

\section{RESUMO}

Esse artigo fazer considerações a respeito da importância da educação para a saúde mental da população negra. Não se trata de falar de educação para a saúde, nem de educação para a prevenção das doenças psíquicas, mas da educação enquanto campo de atualização do conhecimento acerca de si mesmo, enquanto promoção do reconhecimento de si, de construção de identidade cultural, de pertencimento, de integração e solidariedade social e, portanto, da educação como espaço necessário de construção do amor próprio e prática de saúde psíquica.

Palavras-chave: Educação e Relações Raciais; Perspectiva da População Negra; Saúde Mental da População Negra.

\begin{abstract}
This article make considerations about the importance of education for the mental health of the black population. It is not a question of talking about an education for the prevention of mental diseases, but of education while update field of knowledge about himself, while promoting the recognition of other construction of cultural identity, belonging, social integration and solidarity and, therefore, of education as a necessary space of construction of self-esteem and mental health practice.
\end{abstract}

Key-words: education and race relations; perspective of the black population; black population's mental health.

\section{INTRODUÇÃO}

"Precisamos de uma escola menos branca" D. Zilda, Coletivo Ocupa Alemão

"Meus colegas estão sendo exterminados" Fernando, estudante de Letras

Nesse artigo gostaria de fazer algumas considerações a respeito da importância da educação para a saúde mental da população negra. Não se trata de falar de educação para a saúde, nem de educação para a prevenção das doenças psíquicas, mas da educação enquanto campo de atualização do conhecimento acerca de si mesmo, enquanto promoção do reconhecimento de si, de construção de identidade cultural, de 
pertencimento, de integração e solidariedade social e, portanto, da educação como espaço necessário de construção do amor próprio e prática de saúde psíquica.

As duas epígrafes foram proferidas no III Encontro Kitembo: "Povos Afroindígenas, saberes tradicionais e pesquisa em diálogo com a universidade", ocorrido em novembro de 2017, no Instituto de Psicologia da Universidade Federal Fluminense, no esforço que temos feito de pôr em debate as relações étnico-raciais. E na Psicologia, com o propósito de intervir na formação do psicólogo e na produção de conhecimento nas ciências humanas, em relação aos campos da saúde e saúde mental, educação, trabalho, comunidade, sistema prisional e outros nos quais a atuação dos profissionais universitários se insere. Esse debate vem também a propósito da Lei 10.639/2003 (BRASIL, 2003) e Lei 11.645/2008 (BRASIL, 2008), que exigem a inclusão, no currículo oficial da rede de ensino, a obrigatoriedade do estudo da história e cultura afro-brasileira e indígena.

O Coletivo Ocupa Alemão, do Complexo do Alemão, na Cidade do Rio de Janeiro, está criando a Escola Pan-africanista Dandara dos Palmares, conforme nos diz Dona Zilda, membro do Ocupa Alemão, no III Encontro Kitembo. A escola já conta com 25 crianças da localidade, além da presença de crianças avulsas, não para fazer um novo ensino, mas para que as crianças cresçam estudando e aprendendo de outro modo, distinto do modo como o Estado brasileiro passa. Dona Zilda diz: "para que as crianças tenham a vivência de ser pretas e ser da favela. De saber que têm que lutar 24 horas por dia". E complementa: há um "ensino branco que não condiz com a gente". Para D. Zilda as crianças precisam saber quem são e como são. A Escola Dandara dos Palmares, sonhada e agora realizada, pelo coletivo do Complexo do Alemão, dá início a um novo ciclo enquanto comunidade preta, da favela. Assim, conclui Dona Zilda: "quando chegarem na universidade, que cheguem com conhecimento enquanto povo preto".

Ora, a educação que Dona Zilda reclama encontra-se com aquela mesma conforme o trabalho do educador Paulo Freire: "por que não discutir com os alunos a realidade concreta a que se deva associar a disciplina cujo conteúdo se ensina, a realidade agressiva em que a violência é a constante" (Freire, 2013: 32). Para a militante do Ocupa Alemão, como para nosso grande educador, estabelecer a intimidade entre os saberes curriculares e a experiência social dos alunos como indivíduos na sociedade é imprescindível para a função mais radical do ato de educar:

Uma das tarefas mais importantes da prática educativo-crítica é proporcionar as condições em que os educandos em sua relação uns com os outros e todos com o professor ensaiam a experiência profunda do assumir-se. Assumir-se 
Ensino, Saúde e Ambiente-V10 (3), pp. 159-170, Dez. 2017

como ser social e histórico, como ser pensante, transformador. (FREIRE, 2013, p. 41).

Esta assunção de si é básica para o sentimento de pertencimento, a formação da identidade, e o desenvolvimento da solidariedade social, segundo a concepção de Paulo Freire, a percepção de Dona Zilda e aquilo que os movimentos negros creem ser necessário desenvolver entre a população negra e quiçá a população brasileira em geral. Caminho necessário para fazer frente à modulação que os processos econômicosliberais têm aplicado às populações do mundo, transformando-nos em pessoas sem referência social, sem comunidade, sem pertencimento histórico.

Dona Zilda deu sua contribuição ao debate do III Encontro Kitembo e indicou a exigência que devemos fazer à educação escolar: a de trazer aos alunos sua história; o debate de quem são; a experiência profunda do assumir-se, a formação cidadã; ou seja, daquele capaz de reconhecer os problemas históricos da sua comunidade e dispor-se, em solidariedade e coletivamente, ao trabalho de superá-los. Estamos aí no âmago do debate acerca da formação educacional que mantém o educando organicamente conectado aos problemas de sua comunidade. Queremos uma educação "orgânica”, vale dizer, aquela que mantem a conexão dos indivíduos educandos com a situação atual e o devir da sua comunidade.

O ano 1931 viu nascer a Frente Negra Brasileira. Anos antes, entretanto, surgiam várias associações e jornais no Estado de São Paulo, como o Clarim da Alvorada, criado em 1924, por Jaime de Aguiar e José Correia Leite. Ainda nessa época, floresceu a construção da Consciência Negra, como novo modo de resistência da população afrodescendente, no espaço urbano, no seio da sociedade competitiva (FERNANDEZ, 2013, p. 25). Segundo o sociólogo Eduardo de Oliveira, o termo "negro" fora introduzido, naquele momento, pelo militante Vicente Ferreira, para substituir o termo vazio "homem de cor" (OLIVEIRA, 1974, pp 72-73). Esse momento é de afirmação do ser negro, da produção de reivindicações sociais e discurso sobre si mesmo, da construção do auto-reconhecimento, da percepção de si como grupo e de uma perspectiva social própria do negro brasileiro, no ambiente do que Florestan Fernandes chama de sociedade inclusiva ou sociedade competitiva (FERNANDES, 2013: 38-40). É uma experiência existencial nova para a população afrodescendente e, nesse contexto, a emergência do movimento negro. A auto-organização enquanto classe social no interior da sociedade capitalista traz a percepção da importância da educação como determinante no sofrimento mental e adoecimento, mas também como 
determinante da saúde em geral e do desenvolvimento da população negra. Os movimentos negros, que se iniciam nos anos 1920, elegem a educação como imprescindível e reivindicam uma educação nova, integral, radical, que afirme o negro na história do Brasil (FERNANDES, 2013, p. 38).

É da falta dessa educação mencionada pelos ativistas que circulavam no entorno da Frente Negra, que Fernando, 20 anos, estudante de Letras, morador até os 18 anos de sua vida na Cidade de Queimados, na Baixada Fluminense, participante do III Encontro Kitembo, se refere quando constata: "muitos dos seus amigos já foram mortos". O testemunho de algo dessa natureza por um jovem é impactante. Fernando denuncia que a grade curricular do Curso de Graduação em Letras, na faculdade onde estuda, nada consta da população negra, do extermínio da população negra, da literatura deixada por escritores negros - como Luiz Gama, Cruz e Sousa, Sousândrade, Maria Firmina, e outros - "embora minha formação seja para trabalhar com pessoas e é necessário saber quem são essas pessoas”, como diz Fernando. Que os profissionais de Letras, de Psicologia, de Educação e na verdade todos os demais universitários, vão trabalhar com pessoas, é uma noção importante. Trata-se de um trabalho, portanto, de formação de cidadãos, em primeiro lugar, que devem reconhecer-se a si mesmos no processo histórico, social, comunitário de construção do nosso país e de preparação para atender às necessidades da população brasileira.

O Parecer do Conselho Nacional de Educação, de 2004, sobre as Leis 10.639 de 2003, cuja relatoria foi da docente e ativista negra Petronilha Beatriz Gonçalves e Silva, ao se voltar aos dirigentes da nossa nação e aos educadores, afirma a necessidade do "reconhecimento e valorização da história e cultura dos afro-brasileiros" e "indígena" (BRASIL, 2004: 2), quando pretenderem dialogar com os sistemas de ensino, escolas e educadores. Esse direito à educação de qualidade a que o Parecer se refere, é o mesmo que os militantes da Frente Negra estabeleceram; Dona Zilda chama de uma educação menos branca; e o que Paulo Freire considera uma educação para a formação da "identidade cultural” (FREIRE, 2013: 41). O "direito dos negros (e dos povos indígenas) se reconhecerem na cultura nacional, expressarem visões de mundo próprias, manifestarem-se com autonomia" (BRASIL, 2004: 02). A educação assim conduzida, orientada por educadores qualificados, conforme o Parecer, é indispensável para que os cidadãos brasileiros aprendam a "lidar com as tensas relações produzidas pelo racismo" (BRASIL, 2004: 2). O Parecer trata a educação, assim formulada, como fator de reparação do "dano psicológico" que acomete a população afrodescendente. A 
educação é assim, prevenção de doenças, meio de cura e de formação da vida saudável. Parece evidente que, ao debater a respeito da educação escolar, os ativistas negros de outrora e os de agora, enfocam o lugar da educação para a saúde psíquica da população negra.

A Lei 8.080 de 1990, Lei Orgânica da Saúde, nos coloca diante das condições para a promoção, proteção e recuperação da saúde: "a alimentação, a moradia, o saneamento básico, o meio ambiente, o trabalho, a renda, a educação, o transporte, o lazer e o acesso aos bens e serviços essenciais" (BRASIL, 1990). Importante citar também a PNSIPN - Política nacional de Saúde Integral da População Negra (BRASIL, 2007), construída no diálogo e da co-responsabilidade do Estado e da sociedade, sob a insígnia da transversalidade, resultado portanto da luta histórica pela democratização da saúde, encampada pelos movimentos sociais e em especial pelo movimento negro. A PNSIPN tem como diretriz o desenvolvimento de uma educação nacional capaz de desconstruir estigmas e preconceitos e fortalecer a identidade negra (BRASIL, 2007). Nesse artigo queremos, em suma, retomando os sentidos históricos das nossas lutas e reivindicações e o sentido do ativismo negro, enfocar a importância da educação como construtor de nossa subjetividade, reparador de danos psíquicos e restaurador da saúde mental. Não se trata aqui de tomar a educação na prevenção à doença, prevenir para evitar algo, como muitas vezes se faz (ALMEIDA, 1998). Aqui, na medida em que a educação, no sentido dito por Freire, volta-se para a realização de si, ou "assunção de nós por nós mesmos" (FREIRE, 2013: 41) ela repara os danos da subjetividade e tornase ela mesma condição da saúde mental.

A educação, como os outros condicionantes listados no texto da Lei (BRASIL, 1990), é construtor de saúde e importante para o desenvolvimento de modos de vida, para a construção de si mesmo e do amor a si próprio, para desenvolver a experiência de pertencimento histórico e afetivo com sua família, com seu povo, sua terra, seu país. Uma educação que nos propicie a assunção de nós mesmos, nossa história, nossa ascendência, nossas lutas, como diz Paulo Freire (2013). Com a educação, as crianças e os jovens encontram sua história, de onde vieram, a que povo pertencem: "não é isso Dona Zilda?”. A educação como elaboração da memória de nosso percurso civilizatório e de nossas lutas, é uma reivindicação da população negra, dos favelados, dos povos indígenas, dos quilombolas e de todas as raças insurgentes. Não apenas a memória do passado, mas a memória de porque moramos em determinada parte da cidade, porque falamos de determinado modo, porque temos determinado futuro, porque 
empreendemos determinadas lutas, porque cultuamos as forças da natureza e as entidades dos caboclos.

Os Cadernos de Atenção Básica, do Ministério da Saúde, centram-se no conceito ampliado de saúde, na integralidade e na produção de cidadania e autonomia para propagar o "viver saudável” (BRASIL, 2009: 08). Não vemos que se trata de uma alternativa de saúde, ou conceito ampliado de saúde, mas de uma perspectiva rigorosa da saúde. Conforme estes Cadernos voltados para a saúde e a educação:

\begin{abstract}
A escola deve ser entendida como um espaço de relações, um espaço privilegiado para o desenvolvimento crítico e político, contribuindo na construção de valores pessoais, crenças, conceitos e maneiras de conhecer o mundo e interfere diretamente na produção social da saúde. (BRASIL, 2009, p. 08).
\end{abstract}

Cabe à comunidade preta se apropriar de si como força protagonista da sociedade brasileira e fazer realizar aquilo de que necessita para o seu desenvolvimento como sujeito comunitário saudável, autônomo e cidadão, vale dizer, para seu "bemviver", como proclamavam as mulheres na Marcha das Mulheres Negras e que se intitulam "mulheres negras brasileiras, descendentes das aguerridas quilombolas e que lutam pela vida" (MARCHA, 2015: 01). É certo que só nós negros e negras sentimos o racismo com sua pungente dor e somos nós que devemos protagonizar a produção de conhecimento acerca dele, trazendo dessa experiência existencial nossa própria perspectiva. O esforço de organização de uma pauta reivindicatória, iniciada nos anos 1920, facultou à população afrodescendente uma perspectiva social própria, construída na experiência existencial do negro na história do Brasil, desde a chegada dos povos bantos à colônia, passando pela abolição, a formação da República, até os dias atuais. Tal perspectiva foi reconhecida já nos anos 1930, pelos ativistas que estavam em torno do jornal "O clarim da madrugada" e da Frente Negra. O negro traz uma perspectiva social autônoma e precisamos desenvolvê-la no campo de atuação da Psicologia, da Educação e das Ciências Humanas e Sociais como um todo. O gravíssimo problema de saúde da maioria da população brasileira, que é o preconceito racial, já era indicado pelos movimentos negros emergentes na sociedade competitiva.

$\mathrm{Na}$ escola e nos processos educativos em geral, trata-se da assunção da identidade cultural e construção da memória. A educação vai ser o solo fértil para o amor próprio dos negros e das negras, o orgulho de si, de sua família, de seu povo; da contínua vontade de transformação de si que acompanha as comunidades negra e indígena. No candomblé, a manutenção, transmissão e desenvolvimento da tradição 
ocorre pela pedagogia da oralidade, que se dá no encontro do mais velho com o mais novo, no qual ambos aprendem. Na escola, o livro e a escrita são os suportes, mas aqui é também o espaço do encontro no qual educador e educando aprendem, como diz Paulo Freire (1982). Educação que é construção do sonho (FREIRE, 1982), ato de conhecimento do mundo e de si. Como no candomblé, a educação da população negra deve trazer a transversalidade da educação espiritual, isto é, daquela que nos coloca ante a responsabilidade de nós conosco, com a comunidade e com o mundo.

$\mathrm{Na}$ escola atual de configuração branca, a invisibilidade da memória do negro se aprofunda. Assim, a criança ou o adolescente vão sentir, em silêncio, o desterro, os efeitos danosos da diáspora, a falta de referências epistêmicas que nos contemple e de pertencimento histórico e cultural. Crianças e jovens sem referência histórica e sem afeto, perdendo o sentido de existir em comunidade, sugados para o extermínio. Essa educação é co-responsável no extermínio da juventude negra e é ela que se apresenta, como memória recente e dolorosa, na intervenção do jovem Fernando no III Encontro Kitembo, acima descrita. Essa escola nada conta das inúmeras rebeliões dos negros e indígenas desde o início da colonização no Brasil nem da rede de lutas por toda área onde o trabalho escravo ocorreu (MOURA, 2014, p. 182). Ora, a escola precisa falar das lutas dos negros e da resistência das mulheres negras. Precisa promover a compreensão e importância da experiência que foi a República dos Palmares, entre 1630 a 1697; debater sobre a Conjura dos Alfaiates, de 1798; sobre a Guerra de Canudos, na Bahia, entre 1893 a 1897; sobre a Balaiada, no Maranhão, em 1841; Revolta dos Malês, em Salvador, em 1853 e os inumeráveis acontecimentos protagonizados pelos afrodescendentes em sua luta por liberdade e cidadania. Esse conhecimento de nós mesmos e do mundo vai nos dar paz, coragem, confiança, sentido de pertencimento e saúde psíquica.

Há pouco menos de cinco anos, abri a minha pequena biblioteca para o universo de pesquisas publicadas a respeito da formação social brasileira, naquilo que começa em 1546, com a chegada dos primeiros bantos, passa pelas fugas quilombolas, a conjura baiana, a abolição e as primeiras décadas da República que começa em 1889 . Enveredei por novas leituras, justamente ao querer me ocupar de minha própria história, de conhecer a mim e ao meu mundo. Hoje, comprar um livro novo para leitura de nossa ciência social, faz-me lembrar a criança de sete anos que eu fui, ainda hoje vivaz dentro de mim, que ganhava, radiante, a prometida e aguardada caixa de lápis de cor no início do ano escolar. 
Não há dúvida de que as práticas pedagógicas que são vivenciadas no espaço escolar têm poder de marcar, indelevelmente, a vida de quem passa pela escola e, seja de maneira ostensiva seja silenciosa, as práticas escolares são capazes de forjar modos de ser e estar (ALMEIDA, 2009, p. 133).

Esse bloco de lembranças de minha infância e minha estante de livros atual são ilustrações da formação da subjetividade dirigidas no espaço escolar. Em minha infância e adolescência, eu adorava a escola pelas brincadeiras de correr com os colegas, pela merenda, pelo encontro com os professores, pelo estudo dos novos assuntos, mas mais que tudo pelas caixas de lápis de cor que todos os anos eu e outras crianças ganhávamos. Todavia, a escola ficou me devendo o respeito pela minha própria cor preta.

Um livro novo colore o mundo e o torna cheio de diversos objetos, mas cada capítulo que leio a respeito do Brasil, pulo para trás com susto e dor. Entretanto, vemme também a alegria do menino que salta, vê diferente, colore os objetos, as nuvens, o sol, o ar. Esse efeito sempre me salva das tristezas. A minuciosa pesquisa de Florestan Fernandes (2013), publicada no livro A integração do negro na sociedade de classes, em 1965, mostra a assustadora trama da sociedade pós-abolição e da construção da República brasileira, para evitar que os negros trabalhassem e se desenvolvessem: "o negro e o mulato foram eliminados das posições que ocupavam no artesanato urbano pré-capitalista ou no comércio de miudezas e de serviços" (FERNANDES, 2013, p. 41). Neste livro, Florestan mostra a série de efeitos sociopáticos sobre a população negra e modulações de sofrimento psíquico da lógica branca da sociedade.

Li o livro, traduzido e publicado no Brasil em 2005, de Jerry Dávila, Diploma de brancura, gerado de sua pesquisa de doutorado em 1995-1996. Descubro então mais um capítulo triste da história do Rio de Janeiro e do Brasil. Dávila mostra com minuciosidade, por quais modos a política de educação brasileira eliminou, a partir dos anos 1930, as professoras negras que davam aulas para alunos brancos entre $1910 \mathrm{e}$ 1920. No início do século XX, uma extensão considerável de homens negros e mulheres negras trabalhava como professor e professora na rede de ensino do Rio de Janeiro e de todo o país, na qual exercia autoridade, respeito e dignidade sobre crianças brancas em sua maioria (DÁVILA, 2005). A pesquisa de Dávila encontra-se com a de Fernandes, pois se trata agora de um campo particular da estratégia de exclusão dos afrodescendentes, as professoras negras, do trabalho na educação:

Fotografias, artigos de jornal e depoimentos pessoais sugerem que no início do século o número de homens de cor envolvidos no ensino público 
Ensino, Saúde e Ambiente-V10 (3), pp.159-170, Dez. 2017

diminuiu, seguido por um decréscimo no número de mulheres de cor, até que, na década de 1930 e 1940, a esmagadora maioria de professoras era composta por mulheres brancas (DÁVILA, 2005, p. 152).

Afrânio Peixoto, Anísio Teixeira e outros reformadores dos anos 1930, criaram os institutos de educação que selecionavam com critérios eugenistas as futuras professoras, excluíam as mulheres negras e definiram o ensino como profissão branca. Os reformadores participavam do mesmo movimento eugênico da medicina, e como fizeram os médicos, consideravam que os negros não tinham as qualidades morais e de saúde para continuarem professores. A limpeza racial a que se seguiu no início do século XX atingiu a eliminação dos postos de trabalho em todas as frentes. Os critérios psicológicos, médicos e pedagógicos de exclusão também foram utilizados, para exclusão dos afrodescendentes, na Guarda Civil das cidades (DÁVILA, 2005) e, por contágio, em diversos outros campos de trabalho da sociedade brasileira. De modo que, à população negra sobraram os empregos de mais baixa remuneração, como o trabalho das domésticas nas residências das madames brancas, o subemprego, como o que vemos nos sinais trânsito e o desemprego.

Em Minas Gerais, com a chegada, em 1929, da Helena Antipoff, a convite da Secretária de Educação de Minas Gerais, sob a gerência do secretário Francisco Campos, para participar da reforma educacional que se implantava, também imbuída do pensamento eugênico, a Psicologia, no campo da educação, desenvolvia-se na construção do ideal de nação civilizada e domesticação da família mal constituída, desequilibrada, das mulheres e crianças (PINTO, 2005), para evitar a geração de futuras doenças, delinquentes e criminosos das cidades. A educação deveria redimir os brasileiros degenerados e para isso nada sobre os negros seria mais lembrado nem considerado. Era a face cultural do extermínio dos saberes afrodescendentes e indígenas. Giane Almeida, em sua pesquisa sobre a memória de mulheres negras na educação, na cidade de Juiz de Fora, também constata: “à medida que avançam as primeiras décadas do século $\mathrm{XX}$, a população negra, que antes se representava pela presença de professores e alunos, vai, aos poucos, desaparecendo" (ALMEIDA, 2009: 164).

Em Ordem média e norma familiar, publicado em 1974, o médico e psicanalista Jurandir Freire Costa mostrava como a prática psiquiátrica aliada ao projeto de higiene racial e branqueamento na formação da identidade nacional, encontrava-se distante das necessidades da população brasileira (COSTA, 1983). Esta constatação é 
observada também pelos pesquisadores da educação: "a preocupação de instruir o povo aparece sempre vinculada a interesses que fogem aos anseios das classes populares, estando incluída, aí, a grande maioria da população negra” (ALMEIDA, 2009: 168).

No Brasil, como aconteceu na Alemanha, na França e em toda a Europa, as instituições escolares foram eleitas como espaço de aplicabilidade para as teorias eugênicas. No projeto de construção do Brasil como nação civilizada, os afrodescendentes e indígenas estavam sendo exterminados. As mais diversas categorias de intelectuais, e, sobretudo, os da Psicologia, distanciados de relações com a população negra ou indígena, induzida pelas políticas de segregação racial que as elites coordenavam, beneficiados com tais políticas de Estado, aceitaram a opção recalcadora e sublimadora oferecida pela ideologia da democracia racial, bem desenvolvida por Gilberto Freyre, jamais envidaram esforços em descortinar e denunciar a tragédia que é em termos de sofrimento psíquico a estratégia de poder desse nosso Estado nacional.

\section{CONSIDERAÇÕES FINAIS}

É urgente a necessidade de revermos a história das práticas profissionais da Psicologia e da Educação no Brasil, desde a chegada dos negros em 1546, a partir do que Florestan Fernandez chamou de perspectiva social do negro. Esta revisão da produção de conhecimento e das nossas práticas não é ingênua, mas segue a inspiração de Frantz Fanon, cartógrafo do agenciamento colonial da sujeição negra, que nos sugere a criação de meios contracoloniais de luta. A educação que os movimentos negros indicam como necessária para a sociedade, a educação que desejamos, nos ajuda certamente na libertação do complexo colonial, que ainda nos sujeita, de nossas cidades. A Psicologia começa a se engajar da criação de "políticas de cunho inclusivo no âmbito da educação" (CFP, 2017: 66) e esperamos que a Pedagogia e os estudos da Educação avançam nesse sentido. A recém fundada Escola Pan-africanista Dandara dos Palmares e muitos outros projetos educacionais do país, além de toda a rede de ensino na qual crianças e jovens os afrodescendentes e indígenas estudam, aguardam esse avanço. Dona Zilda, os ativistas do Kitembo, Fernando e muita gente negra trabalha para que a educação se torne esse importante campo produtor da saúde da população negra.

\section{REFERENCIAS}

ALMEIDA, G. E. S. Entre Palavras e Silêncios: Memórias da Educação de Mulheres Negras em Juiz de Fora - 1950/1970. Mestrado/UFF, 2009, fl. 315. 
ALMEIDA, S. F. C. O papel da escola na educação e prevenção em saúde mental. Estilos clín. 1998, vol.3, n.4, pp. 112-119. Disponível em: http://pepsic.bvsalud.org/scielo.php?script=sci_arttext\&pid=S1415-

71281998000100015\&lng=pt\&nrm=iso. Acesso em 16/11/ 2017.

BRASIL. Ministério da Saúde. Cadernos de Atenção Básica, n. 24, Brasília: Ministério da Saúde, 2009.

BRASIL. Lei 10.639/2003, estabelece a obrigatoriedade do ensino de História e Cultura Afro-Brasileira e Africana na Educação Básica. 2003.

BRASIL, Ministério da Educação - Conselho Nacional de Educação. Parecer CNE/CP n. ${ }^{\circ}$ 3/2004, das Leis 10.639. 2004.

BRASIL. Lei 11.645, de 2008. Altera a Lei no 9.394, de 20 de dezembro de 1996, modificada pela Lei 10.639, de 9 de janeiro de 2003, e inclui no currículo oficial da rede de ensino a obrigatoriedade da temática "História e Cultura Afro-Brasileira e Indígena".

BRASIL. Lei 8.080 de 1990. Dispõe das condições para a promoção, proteção e recuperação da saúde, organização e o funcionamento dos serviços correspondentes. 1990.

BRASIL, Ministério da Saúde, Secretaria de Gestão Estratégica e Participativa. Política Nacional de Saúde Integral da População Negra - PNSIPN. Brasília, 2007.

COSTA, J. F. História da psiquiatria no Brasil: um recorte ideológico. Rio de Janeiro: Garamond, 2006.

CARNEIRO, A. S. A Construção do Outro como Não-Ser como fundamento do Ser. FEUSP, 2005. (Tese de doutorado). $339 \mathrm{f}$.

CRP - Conselho Federal de Psicologia. Relações Raciais: Referências Técnicas para atuação de psicólogas/os. Brasília: CFP, 2017.

DÁVILA, J. Diploma de brancura: Política social e racial no Brasil - 1917-1945. São Paulo: UNESP, 2006.

OLIVEIRA, E. O. O mulato um obstáculo epistemológico. Revista Argumento, ano 1, n 3, 1974, pp. 65-73.

FANON, F. Pele negra, máscaras brancas. Salvador: EDUFBA, 2008.

FERNANDES, F. A integração do negro na sociedade de classes: o legado da raça branca. São Paulo: Globo, 2013, vol 1.

FREIRE, P. Educação o sonho possível. In BRANDÃO, P. R. (org.) O educador: vida e morte. Rio de Janeiro: Graal, 1982.

FREIRE, P. Pedagogia da autonomia: saberes necessários à prática educativa. Rio de Janeiro: Paz e Terra, 2013.

KABEngElE, M. Prefácio. In CARONE, I. \& BENTO, M. A. S. (orgs.) Psicologia social do racismo: estudos sobre branquitude e branqueamento no Brasil. Petrópolis: Vozes, 2014.

MARCHA. Manifesto da Marcha das Mulheres Negras 2015 contra o Racismo e a Violência e pelo Bem Viver. Brasília, 2015. https://www.geledes.org.br/manifesto-damarcha-das-mulheres-negras-2015-contra-o-racismo-e-violencia-e-pelo-bem-viver (acesso em 02/10/2017).

MARTINS, H. V. As ilusões da cor: sobre raças e assujeitamento no Brasil. Tese doutoramento no Programa de Psicologia USP. São Paulo: 2009.

MOURA, C. Rebeliões da senzala: quilombos, insurreições, guerrilhas. São Paulo: Anita Garibaldi, 2014.

NASCIMENTO, A. O Genocídio do Negro Brasileiro: processo de um racismo mascarado. São Paulo: Perspectiva, 2016. 
PINTO, K. P. Helena Antipoff: o cuidado com a infância e a construção de uma nação civilizada. In DUARTE, L. F. et al (orgs.) Psicologização no Brasil: atores e autores. Rio de Janeiro: Contra Capa Livraria, 2005, pp. 115-125.

VERGNER, C. M. Atrama da besta: a construção cotidiana do genocídio do negro no Rio de Janeiro. Doutorado, Departamento Psicologia, PUC-Rio, 2013, $124 \mathrm{f}$. 